\title{
Analisa Indeks Kinerja Daerah Irigasi Kedung Bantal Kecamatan Pagerwojo Kabupaten Tulungagung dengan Menggunakan Software PDSDA-PAI Versi 2.0
}

\author{
Bintang Sebastian $^{1 *}$, Very Dermawan ${ }^{1}$, Dian Sisinggih ${ }^{1}$ \\ ${ }^{1}$ Jurusan Teknik Pengairan, Fakultas Teknik, Universitas \\ Brawijaya, Jl. M.T. Haryono 167, Malang, (65145), INDONESIA \\ *Korespondensi Email: bintang.sebastian1@gmail.com
}

\begin{abstract}
The cause of food shortages in several areas in Tulungagung Regency is due to a decrease in agricultural productivity as a result of a decrease in the performance of the irrigation system, such as what happened in the Kedung Bantal Irrigation Area. In an effort to prevent the decline in the performance of the irrigation system, monitoring of the performance of the irrigation system is conducted. Irrigation system performance index is needed to determine feasibility and solutions, so to simplify the calculation of the irrigation system performance index value helped by using the PDSDA-PAI Version 2.0 software. Based on the results of the irrigation system performance index assessment using the PDSDAPAI version 2.0 software, the performance index value was $77.35 \%$, while for the calculation of the irrigation system performance index value using blank, the performance index value was $74.13 \%$. The difference in the calculation of the irrigation system performance index value that occurs is due to differences in the assessment parameters between the PDSDA-PAI Version 2.0 software and blanks, however the results of the assessment of the two methods state that the conditions of the Kedung Bantal Irrigation Area are in good condition and only require maintenance activities.
\end{abstract}

Keywords: irrigation assets, irrigation performance, pdsda pai, priority handling scale

Abstrak: Penyebab terjadinya kekurangan pangan di beberapa wilayah di Kabupaten Tulungagung dikarenakan adanya penurunan produktivitas pertanian sebagai dampak dari penurunan kinerja sistem irigasi, seperti yang terjadi pada Daerah Irigasi Kedung Bantal. Sebagai upaya untuk mencegah turunnya kinerja sistem irigasi maka dilakukan pemantauan terhadap kondisi kinerja sistem irigasi. Indeks kinerja sistem irigasi diperlukan untuk menentukan kelayakan dan solusi, sehingga untuk 
mempermudah perhitungan nilai indeks kinerja system irigasi dibantu dengan menggunakan software PDSDA-PAI Versi 2.0. Berdasarkan hasil penilaian indeks kinerja sistem irigasi dengan menggunakan software PDSDA-PAI Versi 2.0 diperoleh nilai indeks kinerja sebesar 77,35\%, sedangkan untuk perhitungan nilai indeks kinerja system irigasi dengan menggunakan blangko didapatkan nilai indeks kinerja sebesar $74,13 \%$. Selisih perhitungan nilai indeks kinerja sistem irigasi yang terjadi disebabkan oleh perbedaan parameter penilaian antara software PDSDAPAI Versi 2.0 dengan blangko, akan tetapi hasil penilaian dari kedua metode menyatakan bahwa kondisi Daerah Irigasi Kedung Bantal dalam keadaan baik dan hanya memerlukan kegiatan pemeliharaan.

Kata kunci: aset irigasi, kinerja irigasi, pdsda pai, skala prioritas penanganan

\section{Pendahuluan}

Negara Indonesia dikenal secara luas sebagai negara agraris. Sebagian besar potensi alam Indonesia terletak pada sektor pertanian yang meliputi kesuburan hutan dan tanah sebagai sumber air maupun iklim yang mendukung sehingga mayoritas penduduk Indonesia lebih memilih untuk bekerja sebagai petani.

Pertumbuhan penduduk Indonesia yang tinggi dari tahun ke tahun menyebabkan peningkatan kebutuhan pangan, sehingga dibutuhkan beberapa upaya agar hasil produksi dalam sektor perkebunan dan pertanian dapat meningkat, dimana perbaikan pada sektor irigasi merupakan salah satu upaya yang mungkin untuk dilakukan. Sebagian penduduk yang tinggal di Kabupaten Tulungagung memilih untuk bekerja pada sektor pertanian. Sektor yang menjadi salah satu unggulan dalam perekonomian Kabupaten Tulungagung yaitu sektor pertanian. Lokasi Daerah Irigasi Kedung Bantal tepatnya berada pada Kecamatan Pagerwojo, Kabupaten Tulungagung.

Para pengguna yaitu para petani dapat merasakan secara langsung dampak dari penurunan kinerja sistem irigasi. Pihak pengelola dalam melakukan pengaturan juga mengalami kesulitan sebagai dampaknya. Apabila tidak dilakukan upaya perbaikan, maka permasalahan ekonomi dan sosial di tingkat masyarakat petani dapat terjadi. Sarana yang rusak dapat dilakukan perbaikan dengan pelaksanaan usaha rehabilitasi maupun pemeliharaan di Daerah Irigasi Kedung Bantal. Sehingga dalam menetapkan layak atau tidak dan menetapkan alternatif yang sesuai untuk mengatasi indeks kinerja sistem irigasi yang mengalami penurunan, dibutuhkan suatu besaran nilai indeks kinerja sistem.

\section{Bahan dan Metode}

\subsection{Bahan}

Daerah studi yang digunakan yaitu Daerah Irigasi Kedung Bantal yang terletak di Kecamatan Pagerwojo Kabupaten Tulungagung. Peta Batas Administrasi Kecamatan Pagerwojo akan ditampilkan pada Gambar 1 berikut: 


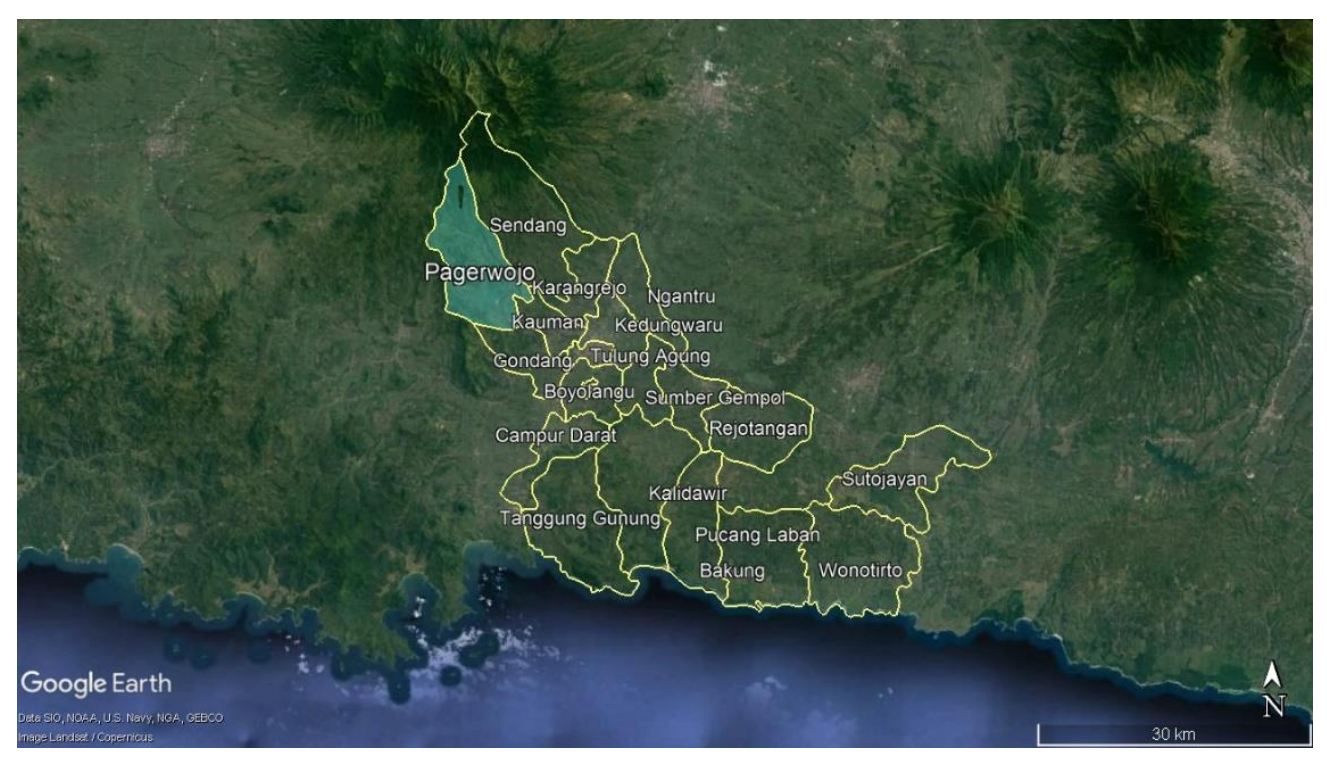

Gambar 1: Peta Batas Administrasi Kecamatan Pagerwojo

Dalam studi yang dilakukan membutuhkan data dengan detail sebagai berikut:

a) Diperlukan Data Primer yaitu kondisi eksisting aset irigasi yang meliputi:

- Skema irigasi

- Dimensi saluran dan bangunan

- Kondisi saluran dan bangunan

- Dokumentasi penelusuran

b) Diperlukan Data Sekunder yang meliputi:

- Luas Layanan

- Data ketersediaan Air

- Data Pendukung

\subsection{Metode}

Penerapan pelaksanaan metode sesuai dengan tahapan sebagai berikut:

a) Data Primer dikumpulkan dengan penelusuran jaringan serta Data Sekunder dikumpulkan dimana data diisi pada dinas terkait)

b) Validasi Data pada dinas terkait

c) Pengolahan dan Analisa Data menggunakan blangko Permen PU No.12 tahun 2015 serta memanfaatkan software sebagai alat bantu yaitu PDSDA-PAI Versi 2.0

d) Pengecekan hasil analisa

e) Menentukan skala prioritas penanganan

\subsection{Persamaan}

Untuk menentukan indeks kinerja sistem irigasi dapat dihitung dengan persamaan: [1]

$$
N K B=\frac{(N B \times N K F)}{100} \quad \text { Pers. } 1
$$


Dengan:

NKB : Nilai Kondisi Bobot (Tiap bangunan irigasi pada dasarnya memiliki Indeks nilai bobot)

NB : Nilai Bobot (Dalam indeks kinerja sistem irigasi, suatu aspek memiliki bobot nilai)

NKF : Nilai kondisi Fisik (Aset irigasi memiliki kondisi tertentu, mengacu pada "Kriteria dan Bobot Penilaian Kinerja Sistem Irigasi")

Sedangkan dalam hal Skala Prioritas dapat dihitung dengan persamaan: [2]

$$
P=\left(K \times 0,35+F^{1,5} \times 0,65\right) \times\left(\frac{A_{a s}}{A_{d i}}\right)^{-0,5} \quad \text { Pers. } 2
$$

Dengan:

$\mathrm{P}=$ Prioritas

$\mathrm{K}=$ Skor Kondisi

$\mathrm{F} \quad=$ Skor Fungsi

$\mathrm{A}_{\mathrm{as}}=$ Luas layanan terpengaruh kerusakan aset

$\mathrm{A}_{\mathrm{di}}=$ Luas daerah irigasi

\section{Hasil dan Pembahasan}

\subsection{Data Teknis dan Kondisi Eksisting DI Kedung Bantal}

Dengan penelusuran jaringan yang dilakukan, didapatkan Data mengenai Aset Bangunan beserta Data mengenai Aset Saluran di DI Kedung Bantal dengan detail pada Tabel 1 berikut:

Tabel 1: Data Rekap Jumlah Aset Bangunan Jaringan Irigasi Kedung Bantal

\begin{tabular}{clc}
\hline No & \multicolumn{1}{c}{ Jenis Aset Bangunan } & Jumlah Aset \\
\hline 1 & Pengambilan Bebas & 1 \\
2 & Sadap & 8 \\
3 & Bangunan Ukur & 2 \\
4 & Kantong Lumpur & 1 \\
5 & Terjunan Pembawa & 9 \\
6 & Talang & 9 \\
7 & Gorong-Gorong & 2 \\
8 & Jembatan Desa & 3 \\
9 & Terjunan Drainase & Total \\
\hline
\end{tabular}

Tabel 2: Data Aset Saluran Jaringan Irigasi Kedung Bantal

\begin{tabular}{|c|c|c|}
\hline No & Jenis Aset Saluran & $\begin{array}{c}\text { Panjang Saluran } \\
(\mathrm{m})\end{array}$ \\
\hline 1 & Saluran Sekunder & 5.84 \\
\hline 2 & Saluran Tersier & 450 \\
\hline & Total & 6.29 \\
\hline
\end{tabular}


Pada Tabel 2 dapat diketahui mengenai Aset saluran serta bangunan yang berlokasi pada DI Kedung Bantal terdapat kerusakan. Hal itu dapat diketahui ketika mengamati hasil dari penelusuran jaringan. Akan tetapi fungsi serta kondisi aset saluran dan bangunan yang terdapat di Daerah Irigasi Kedung Bantal terbilang cukup baik apabila diamati secara umum.

\subsection{Analisa Ketersediaan Air}

Metode Modus-Median merupakan metode yang dipilih dalam studi ini untuk menghitung hasil analisa ketersediaan air, dimana ditemukan debit air memiliki rentang nilai $75-205$ 1/dt.

\subsection{Evaluasi Intensitas Tanam}

Intensitas tanam eksisting pada tahun 2014-2018 di DI Kedung Bantal dapat dilihat pada Tabel 3 berikut, data intensitas tanam tersebut dirata-rata dan kemudian direkapitulasi sehingga didapatkan dari hasil analisa luas pola tata tanam, dimana data luas pola tata tanam tersebut berasal dari UPTD Gondang. Rekapitulasi ditunjukkan sebagai berikut:

Tabel 3: Rekapitulasi Rerata Intensitas Tanam Eksisting Tahun 2014-2018

\begin{tabular}{ccccc}
\hline \multirow{2}{*}{ Tahun } & \multicolumn{4}{c}{ Intensitas Tanam Rerata $(\%)$} \\
& Padi & Palawija & Tebu & Total \\
\hline $2014-2015$ & 257,68 & 29,09 & 9,09 & 295,86 \\
$2015-2016$ & 248,84 & 20,61 & 6,06 & 275,51 \\
$2016-2017$ & 248,74 & 30,30 & 7,07 & 286,11 \\
$2017-2018$ & 211,92 & 24,24 & 10,00 & 246,16 \\
\hline \hline Rerata MH & 83,23 & 9,00 & 2,35 & 94,58 \\
Rerata MK I & 85,76 & 7,02 & 2,88 & 95,66 \\
Rerata MK II & 72,80 & 10,04 & 2,83 & 85,67 \\
Rerata Total & 241,79 & 26,06 & 8,06 & 275,91 \\
\hline
\end{tabular}

UPTD Gondang mengeluarkan Rencana Tata Tanam Global (RTTG), dimana diprogram terdapat tiga kali musim tanam dalam satu tahun, dengan setiap tahunnya memiliki intensitas tanam $300 \%$.

Dalam 5 tahun terakhir (2014-2018) berdasarkan hasil penilaian pada DI Kedung Bantal hanya intensitas tanam rata-rata yang dihasilkan sebesar $275,91 \%$, dimana detailnya yaitu padi memiliki intensitas tanam $241,79 \%$, palawija memiliki intensitas tanam 26,06 $\%$ serta tebu memiliki intensitas tanam $8,06 \%$, oleh karena itu kesimpulan yang didapatkan yaitu rencana tanam yang dirancang memiliki ketidak sesuaian dengan realisasi tanam pada Daerah Irigasi Kedung Bantal.

\subsection{Analisa Kebutuhan Air Irigasi}

Metode FPR-LPR yang dimanfaatkan untuk menghitung kebutuhan air irigasi pada Daerah Irigasi Kedung Bantal, sehingga didapatkan hasil yang ditunjukkan pada Tabel 4. 


\subsection{Analisa Neraca Air}

Daerah Irigasi Kedung Bantal memiliki kondisi neraca air eksisting yang ditunjukkan pada Tabel 4 berikut:

Tabel 4: Analisa Evaluasi Pembagian Air Irigasi Masa Tanam 2014-2015

\begin{tabular}{|c|c|c|c|c|c|}
\hline \multirow{2}{*}{ Bulan } & \multirow{2}{*}{ Periode } & \multirow{2}{*}{$\begin{array}{c}\text { Total Q Keb. } \\
\text { Air Irigasi } \\
\text { (L/dt) }\end{array}$} & \multirow{2}{*}{$\begin{array}{c}\text { Q Andalan } \\
\text { (L/dt) }\end{array}$} & \multicolumn{2}{|c|}{ Evaluasi Pembagian Air } \\
\hline & & & & Faktor K & Kriteria Faktor K \\
\hline & I & 104,490 & 90,200 & 0,863 & Terus Menerus \\
\hline \multirow[t]{3}{*}{ Oct } & II & 98,550 & 77,857 & 0,790 & Terus Menerus \\
\hline & III & 165,000 & 188,625 & 1,143 & Terus Menerus \\
\hline & I & 165,000 & 155,400 & 0,942 & Terus Menerus \\
\hline \multirow[t]{3}{*}{ Nov } & II & 165,000 & 191,821 & 1,163 & Terus Menerus \\
\hline & III & 165,000 & 182,350 & 1,105 & Terus Menerus \\
\hline & I & 165,000 & 171,750 & 1,041 & Terus Menerus \\
\hline \multirow[t]{3}{*}{ Dec } & II & 165,000 & 171,750 & 1,041 & Terus Menerus \\
\hline & III & 165,000 & 162,594 & 0,985 & Terus Menerus \\
\hline & I & 180,875 & 168,500 & 0,932 & Terus Menerus \\
\hline \multirow[t]{3}{*}{ Jan } & II & 145,875 & 166,050 & 1,138 & Terus Menerus \\
\hline & III & 166,000 & 171,750 & 1,035 & Terus Menerus \\
\hline & I & 166,000 & 173,444 & 1,045 & Terus Menerus \\
\hline \multirow[t]{3}{*}{$\mathrm{Feb}$} & II & 166,000 & 173,444 & 1,045 & Terus Menerus \\
\hline & III & 166,000 & 151,286 & 0,911 & Terus Menerus \\
\hline & I & 166,000 & 184,563 & 1,112 & Terus Menerus \\
\hline \multirow[t]{3}{*}{ Mar } & II & 166,000 & 171,500 & 1,033 & Terus Menerus \\
\hline & III & 166,000 & 192,167 & 1,158 & Terus Menerus \\
\hline & I & 166,000 & 188,300 & 1,134 & Terus Menerus \\
\hline \multirow[t]{3}{*}{ Apr } & II & 166,000 & 168,727 & 1,016 & Terus Menerus \\
\hline & III & 166,000 & 162,455 & 0,979 & Terus Menerus \\
\hline & I & 119,000 & 200,667 & 1,686 & Terus Menerus \\
\hline \multirow[t]{3}{*}{ May } & II & 119,000 & 200,667 & 1,686 & Terus Menerus \\
\hline & III & 82,000 & 175,656 & 2,142 & Terus Menerus \\
\hline & I & 82,000 & 175,656 & 2,142 & Terus Menerus \\
\hline \multirow[t]{3}{*}{ Jun } & II & 82,000 & 151,667 & 1,850 & Terus Menerus \\
\hline & III & 82,000 & 151,667 & 1,850 & Terus Menerus \\
\hline & I & 82,000 & 134,250 & 1,637 & Terus Menerus \\
\hline \multirow[t]{3}{*}{ Jul } & II & 82,000 & 155,000 & 1,890 & Terus Menerus \\
\hline & III & 82,000 & 155,000 & 1,890 & Terus Menerus \\
\hline & $\mathrm{I}$ & 82,000 & 136,000 & 1,659 & Terus Menerus \\
\hline \multirow[t]{3}{*}{ Aug } & II & 82,000 & 133,286 & 1,625 & Terus Menerus \\
\hline & III & 81,000 & 138,125 & 1,705 & Terus Menerus \\
\hline & I & 81,000 & 134,000 & 1,654 & Terus Menerus \\
\hline \multirow[t]{2}{*}{ Sep } & II & 81,000 & 134,000 & 1,654 & Terus Menerus \\
\hline & III & 81,000 & 135,500 & 1,673 & Terus Menerus \\
\hline
\end{tabular}


Berikut adalah Grafik 3 yang menerangkan tentang Neraca Air pada Kondisi Eksisting dengan Masa Tanam pada Tahun 2014-2015:

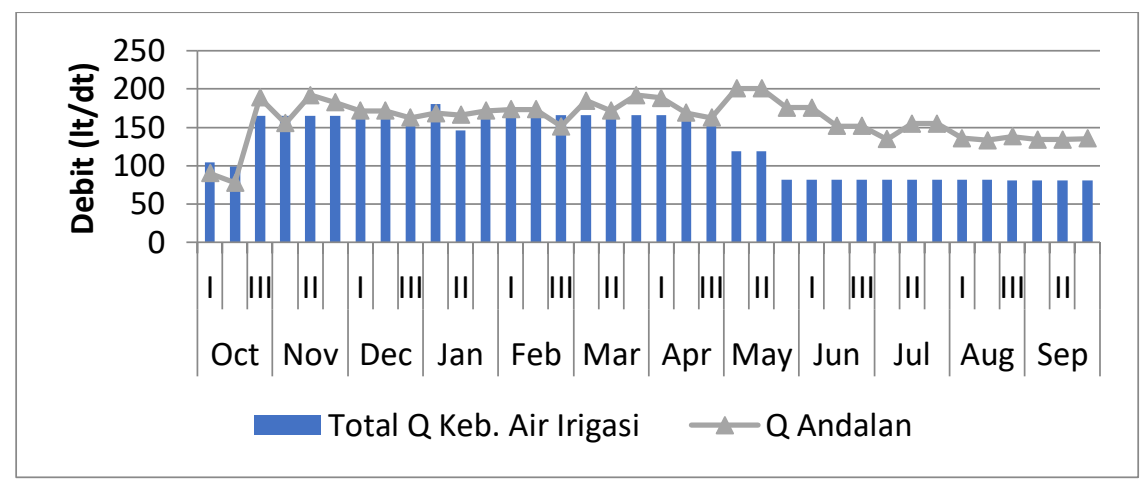

Gambar 3: Grafik Neraca Air Kondisi Eksisting Masa Tanam 2014 - 2015

Berdasarkan hasil analisa neraca air pada kondisi eksisting dengan masa tanam pada Tahun 2014-2015 hingga 2017-2018 dapat disimpulkan bahwa tidak terdapat rekomendasi gilir pada daerah irigasi jika dilihat dari nilai perbandingan antara debit andalan modus ( $\mathrm{Q}_{\text {Modus}}$ ) dengan kebutuhan air, sehingga bias disimpulkan bahwa jumlah ketersediaan air sudah mencukupi kebutuhan air untuk irigasi di Daerah Irigasi Kedung Bantal.

\subsection{Kinerja Jaringan Irigasi}

Pada Daerah Irigasi Kedung Bantal digunakan dua metode untuk melakukan penilaian indeks kinerja yaitu dengan menggunakan blangko berdasarkan lampiran Peraturan Menteri Pekerjaan Umum Nomor 12/PRT/M/2015 dan dengan memanfaatkan software PDSDA-PAI Versi 2.0. Dengan menggunakan blangko berdasarkan lampiran Peraturan Menteri Pekerjaan Umum Nomor 12/PRT/M/2015 mengenai eksploitasi dan pemeliharaan jaringan irigasi maka didapatkan hasil penilaian indeks kinerja sistem pada Daerah Irigasi Kedung Bantal yang tertera pada Tabel 5 berikut:

\section{Tabel 5. Indeks Kinerja DI Kedung Bantal}

\begin{tabular}{|c|c|c|c|c|c|}
\hline \multicolumn{3}{|r|}{ Uraian } & $\begin{array}{c}\text { Nilai Bobot } \\
2 \\
\end{array}$ & $\begin{array}{c}\text { Nilai Kondisi Fisik } \\
\text { (NKF) } \\
3 \\
\end{array}$ & $\begin{array}{c}\begin{array}{c}\text { Nilai Kondisi Bobot } \\
(\mathbf{N K B}) \\
4=(2 \times 3) / 100\end{array} \\
\end{array}$ \\
\hline & \multirow{2}{*}{\multicolumn{2}{|c|}{ PRASARANA FISIK }} & 10 & & 74,13 \\
\hline I. & & & 45 & & $\mathbf{3 4 , 3 0}$ \\
\hline \multirow[t]{14}{*}{1.} & & 13 & & 9,32 \\
\hline & \multicolumn{2}{|c|}{$\begin{array}{l}\text { Bangunan Utama } \\
1.1 \text { Bangunan intake di sungai }\end{array}$} & 5 & & 3,26 \\
\hline & & a. Morfologi (rezim) sungai & 0,75 & 84 & 0,63 \\
\hline & & b. Bangunan intake & 0,75 & 82 & 0,62 \\
\hline & & Sayap pada bangunan intake & 0,75 & 50 & 0,38 \\
\hline & & Lantai pada bangunan intake & 0,75 & 80 & 0,60 \\
\hline & & Tanggul penutup & 0,75 & 62 & 0,47 \\
\hline & & Jembatan dan pagar pengaman diatas bangunan intake & 0,50 & 40 & 0,20 \\
\hline & & g. Papan operasi dan mistar ukur & 0,75 & 50 & 0,38 \\
\hline & \multirow{5}{*}{$\begin{array}{l}1.2 . \\
1.3 .\end{array}$} & Pintu Pengambilan Intake & 4 & 81 & $\mathbf{3 , 2 4}$ \\
\hline & & Kantong Lumpur \& Pintu Pengurasnya. & 4 & & $\mathbf{2 , 8 2}$ \\
\hline & & a. Bangunan Kantong Lumpur & 1,40 & 76 & 1,06 \\
\hline & & b. Kantong Lumpur telah di bersihkan & 1,20 & 65 & 0,78 \\
\hline & & c. Pintu Penguras \& Roda gigi Kantong Lumpur & 1,40 & 70 & 0,98 \\
\hline \multirow[t]{4}{*}{2.} & \multicolumn{2}{|r|}{ Saluran Pembawa } & 10 & & 8,14 \\
\hline & & $\begin{array}{l}\text { Kapasitas tiap saluran cukup untuk membawa debit kebutuhan / } \\
\text { Rencana maksimum. }\end{array}$ & 5 & 83 & 4,15 \\
\hline & 2.2 . & $\begin{array}{l}\text { Tinggi tanggul cukup untuk menghindari limpahan setiap saat } \\
\text { selama pengoperasian. }\end{array}$ & 2 & 84 & 1,68 \\
\hline & 2.3 . & Semua perbaikan saluran telah selesai. & 3 & 77 & 2,31 \\
\hline
\end{tabular}


Lanjutan Tabel 5. Indeks Kinerja DI Kedung Bantal

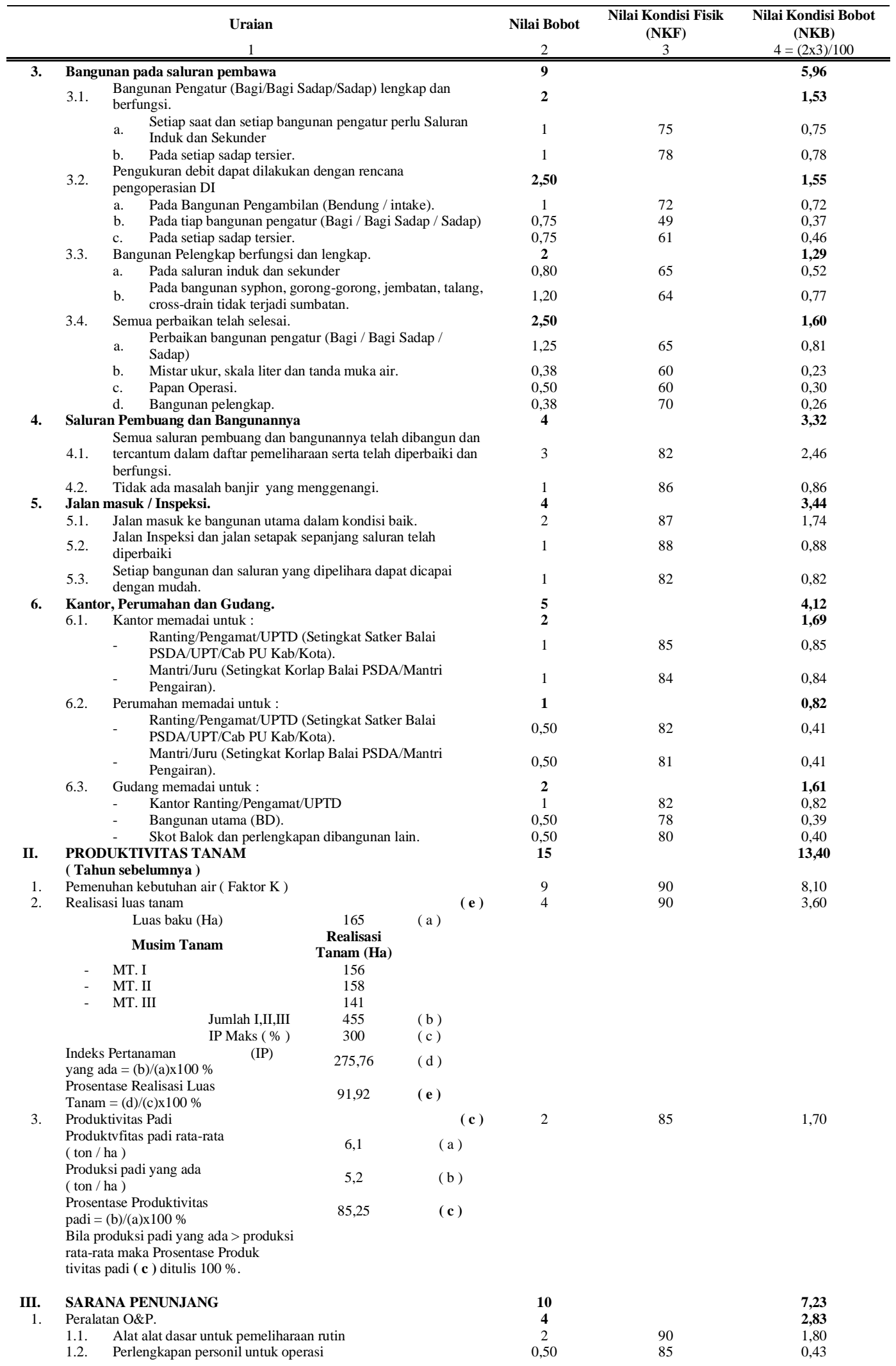


Lanjutan Tabel 5. Indeks Kinerja DI Kedung Bantal

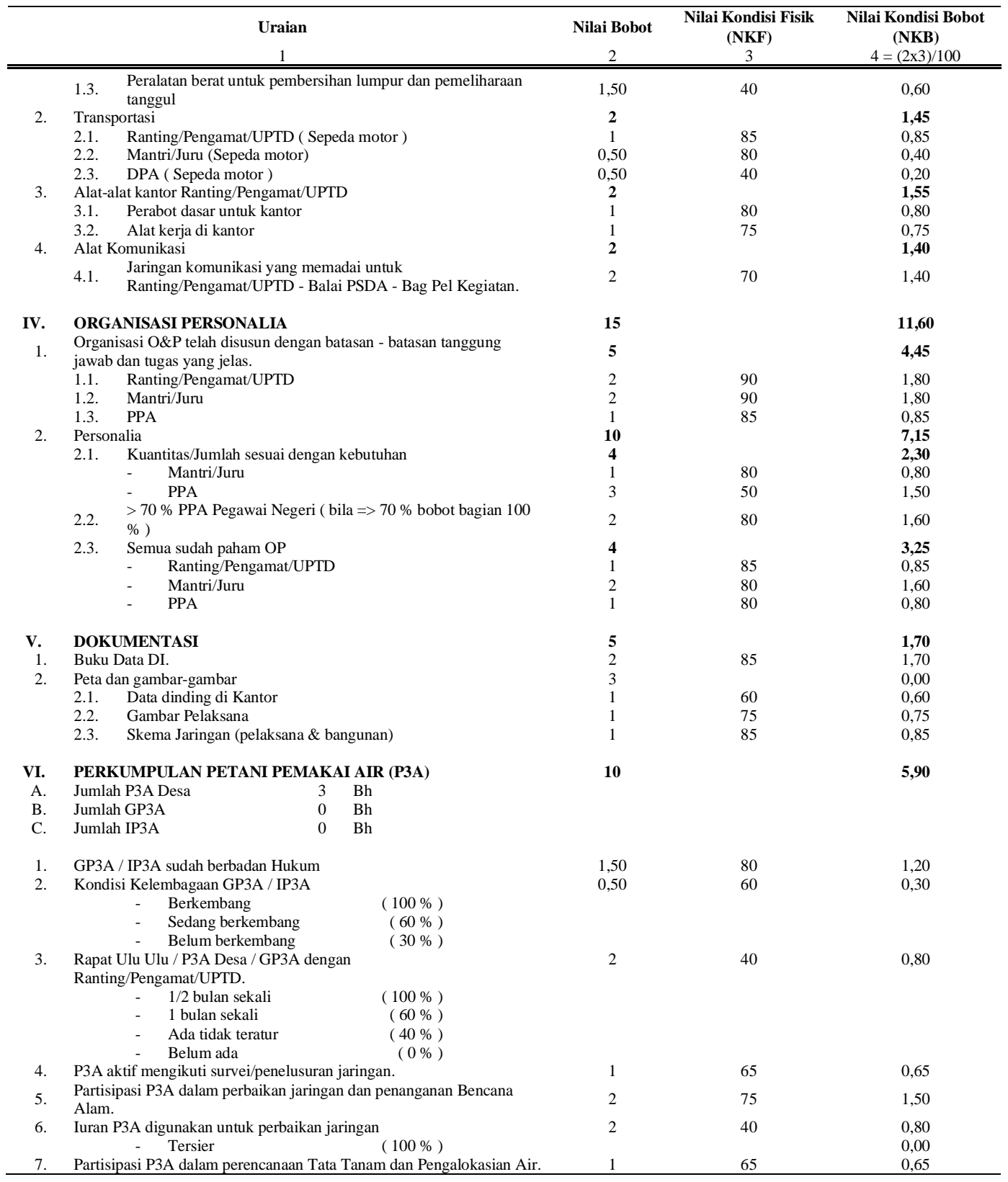

Keterangan:

1. Uraian dari Parameter untuk tiap Kondisi

2. Bobot Nilai (Dalam indeks kinerja sistem irigasi, suatu aspek memiliki bobot nilai)

3. Nilai Kondisi Fisik/NKF, mengacu pada "Kriteria dan Bobot Penilaian Kinerja Sistem Irigasi")

4. Nilai Kondisi Bobot (NKB) diperoleh dari Persamaan 1

Berdasarkan perhitungan sebelumnya, nilai indeks pada setiap aspek dapat dilakukan rekapitulasi, yang ditunjukkan sesuai Tabel 6 berikut: 
Tabel 6. Rekapitulasi Indeks Kinerja Blangko

\begin{tabular}{|c|c|c|c|c|c|}
\hline \multirow[b]{2}{*}{ No. } & \multirow[b]{2}{*}{ Perihal } & & \multicolumn{3}{|c|}{ Nilai Kondisi Bobot } \\
\hline & & & $\begin{array}{c}\text { Yang Ada } \\
\%\end{array}$ & $\begin{array}{c}\text { Maks } \\
\%\end{array}$ & $\underset{\%}{\operatorname{Min}}$ \\
\hline 1. & Prasarana Fisik & : & 34,30 & 45 & 25 \\
\hline 2. & Produktivitas tanam & : & 13,40 & 15 & 10 \\
\hline 3. & Sarana Penunjang & : & 7,23 & 10 & 5 \\
\hline 4. & Organisasi Personalia & : & 11,60 & 15 & 7,5 \\
\hline 5. & Dokumentasi & : & 1,70 & 5 & 2,5 \\
\hline 6. & P3A & : & 5,90 & 10 & 5 \\
\hline & JUMLAH & : & 74,13 & $\overline{100}$ & $\overline{55}$ \\
\hline
\end{tabular}

Selanjutnya dengan software PDSDA-PAI Versi 2.0 dilakukan running sehingga diperoleh indeks kinerja, seperti yang tertera pada Tabel 7 berikut:

Tabel 7. Rekapitulasi Indeks Kinerja PDSDA-PAI

\begin{tabular}{clccc}
\hline & & \multicolumn{3}{c}{ Nilai Kondisi Bobot } \\
No. & & Yerihal & Maks & Min \\
& & & $\%$ & $\%$ \\
\hline \hline 1 & Kondisi Prasarana & 28,51 & 45 & 25 \\
2 & Ketersediaan Air & 8,70 & 9 & 6 \\
3 & Indeks Pertanaman & 5,80 & 6 & 4 \\
4 & Sarana Penunjang & 8,61 & 10 & 5 \\
5 & Organisasi Personalia & 13,32 & 15 & 7,5 \\
6 & Dokumentasi & 4,45 & 5 & 2,5 \\
7 & P3A & 7,95 & 10 & 5 \\
\hline \hline & JUMLAH & 77,35 & 100 & 55 \\
\hline
\end{tabular}

Sebagai bahan pertimbangan, pada Tabel 8 akan disampaikan paparan hasil perbandingan perhitungan nilai indeks kinerja apabila dihitung dengan menggunakan blangko yang tertera di lampiran Peraturan Menteri Pekerjaan Umum Nomor 12/PRT/2015 dengan hasil/output yang dilakukan dari proses running dengan menggunakan bantuan aplikasi PDSDA-PAI Versi 2.0:

Tabel 8. Perbandingan Nilai Indeks Kinerja Sistem Irigasi DI Kedung Bantal

\begin{tabular}{clcc}
\hline \multirow{2}{*}{ No. } & \multicolumn{1}{c}{ Peri`hal } & \multicolumn{2}{c}{ Indeks Kinerja Saat Ini } \\
& \multicolumn{1}{|c}{ Blangko } & Software PDSDA-PAI Versi 2.0 \\
\hline \hline 1 & Kondisi Prasarana & 34,30 & 28,51 \\
2 & Ketersediaan Air & 13,40 & 8,70 \\
3 & Indeks Pertanaman & 7,23 & 5,80 \\
4 & Sarana Penunjang & 8,61 \\
5 & Organisasi Personalia & 11,60 & 13,32 \\
\hline
\end{tabular}


Lanjutan Tabel 8. Perbandingan Nilai Indeks Kinerja Sistem Irigasi DI Kedung Bantal

\begin{tabular}{|c|c|c|c|}
\hline \multirow{2}{*}{ No. } & \multirow{2}{*}{ Perihal } & \multicolumn{2}{|c|}{ Indeks Kinerja Saat Ini } \\
\hline & & B`langko & Software PDSDA-PAI Versi 2.0 \\
\hline 6 & Dokumentasi & 1,70 & 4,45 \\
\hline \multirow[t]{2}{*}{7} & $\mathrm{P} 3 \mathrm{~A}$ & 5,90 & 7,95 \\
\hline & JUMLAH & 74,13 & 77,35 \\
\hline
\end{tabular}

Berdasarkan hasil analisa dapat dilihat bahwa terdapat beberapa perbedaan nilai pada aspek indeks kinerja sistem irigasi antara perhitungan dengan menggunakan software PDSDA-PAI dan dengan menggunakan blangko. Perbedaan besarnya nilai indeks tersebut dapat terjadi karena adanya beberapa perbedaan kriteria penilaian kondisi sehingga dapat terjadi selisih nilai, yakni sebesar 3,22\%.

Setelah melakukan analisa perhitungan nilai indeks kinerja sistem irigasi dengan kedua metode diatas, diperoleh informasi bahwa besarnya nilai indeks kinerja sistem irigasi pada Daerah Irigasi Kedung Bantal berada diantara 74-77\%, sehingga kinerja jaringan irigasi Kedung Bantal termasuk dalam kategori baik.

\subsection{Skala Prioritas Penanganan}

Software PDSDA-PAI Versi 2.0 yang digunakan untuk menghitung analisa skala prioritas pada penanganan aspek prasarana fisik menggunakan pedoman dari Peraturan Menteri Pekerjaan Umum no 23/PRT/M/2015 tentang Pengelolaan Aset Irigasi.

Urutan penanganan yang diperoleh dari perhitungan dapat dilakukan analisa ulang, mengingat urutan penanganan tersebut didapatkan berdasarkan Persamaan 2, dimana kerusakan aset tidak menjadi pertimbangan efektivitas dari sistem irigasi Analisa ulang dalam upaya menentukan urutan skala prioritas penanganan aset dilakukan secara bertahap. Tahapan awal yang dilakukan yaitu skala prioritas penanganan diurutkan berdasarkan skor prioritas, selanjutnya berdasarkan urutan tingkat urgensi dilakukan proses sorting data.

Berdasarkan pada waktu dilakukannya penanganan suatu aset irigasi beserta pertimbangan mengenai dampak kerusakan pada aset jaringan irigasi dengan kaitannya pada efektivitas sistem jaringan irigasi, maka dapat ditentukan urutan tingkat urgensi. Selanjutnya untuk analisa dan hasil bisa dilihat pada Tabel 9 berikut:

Tabel 9. Urutan Prioritas Penanganan

\begin{tabular}{lllcc}
\hline No & \multicolumn{1}{c}{ Aset } & Nomenklatur & $\begin{array}{c}\text { Skor } \\
\text { Prioritas }\end{array}$ & $\begin{array}{c}\text { Tingkat } \\
\text { Urgensi }\end{array}$ \\
\hline \hline 1 & Bangunan Ukur & B.KB.2b & 1,00 & SU \\
2 & Talang & B.KB.2m & 1,00 & JP \\
3 & Talang & B.KB.2n & 1,00 & SU \\
4 & Terjunan Pembawa & B.KB.8a & 1,12 & SU \\
5 & Saluran Sekunder Pembawa & R.KB.2 & 2,20 & SU \\
6 & Talang & B.KB.2h & 2,54 & KU \\
7 & Talang & B.KB.2i & 2,54 & SU \\
8 & Talang & B.KB.2j & 2,54 & KU
\end{tabular}


Lanjutan Tabel 9. Urutan Prioritas Penanganan

\begin{tabular}{cllcc}
\hline No & \multicolumn{1}{c}{ Aset } & Nomenklatur & $\begin{array}{c}\text { Skor } \\
\text { Prioritas }\end{array}$ & $\begin{array}{c}\text { Tingkat } \\
\text { Urgensi }\end{array}$ \\
& & & & \\
\hline \hline 9 & Talang & B.KB.3a & 2,55 & JP \\
10 & Terjunan Pembawa & B.KB.7b & 2,64 & KU \\
11 & Terjunan Pembawa & B.KB.7c & 2,64 & SU \\
12 & Terjunan Pembawa & B.KB.8c & 2,84 & JP \\
13 & Terjunan Pembawa & B.KB.8d & 2,84 & JP \\
14 & Terjunan Pembawa & B.KB.8e & 2,84 & SU \\
15 & Sadap & B.KB.3 & 3,09 & JP \\
16 & Sadap & B.KB.5 & 3,90 & JP \\
17 & Saluran Sekunder Pembawa & R.KB.1 & 4,08 & SU \\
18 & Saluran Sekunder Pembawa & R.KB.6 & 4,25 & UR \\
19 & Pengambilan Bebas & B.KB.1 & 4,43 & SU \\
20 & Kantong Lumpur & B.KB.2a & 4,43 & SU \\
21 & Terjunan Drainase & B.KB.2c & 4,43 & JP \\
22 & Talang & B.KB.2d & 4,43 & JP \\
23 & Talang & B.KB.2e & 4,43 & JP \\
24 & Talang & B.KB.2f & 4,43 & SU \\
25 & Terjunan Drainase & B.KB.2g & 4,43 & UR \\
26 & Gorong-Gorong & B.KB.21 & 4,43 & JP \\
27 & Saluran Sekunder Pembawa & R.KB.4 & 4,51 & UR \\
28 & Saluran Sekunder Pembawa & R.KB.7 & 4,56 & SU \\
29 & Bangunan Ukur & B.KB.6a & 4,57 & JP \\
30 & Sadap & B.KB.6 & 4,57 & SU \\
31 & Saluran Sekunder Pembawa & R.KB.5 & 4,57 & JP \\
32 & Sadap & B.KB.7 & 4,61 & SU \\
33 & Sadap & B.KB.8 & 4,95 & JP \\
34 & Sadap & B.KB.4 & 5,11 & UR \\
35 & Terjunan Pembawa & B.KB.9b & 6,16 & SU \\
36 & Gorong-Gorong & B.KB.2k & 6,60 & JP \\
37 & Sadap & B.KB.2 & 6,60 & SU \\
38 & Saluran Sekunder Pembawa & R.KB.3 & 6,68 & UR \\
39 & Jembatan Desa & B.KB.5a & 6,72 & JP \\
40 & Jembatan Desa & B.KB.7a & 6,88 & JP \\
41 & Terjunan Pembawa & B.KB.8b & 7,38 & UR \\
42 & Terjunan Pembawa & B.KB.9a & 10,75 & JP \\
43 & Saluran Sekunder Pembawa & R.KB.8 & 10,75 & UR \\
44 & Sadap & B.KB.9 & 14,37 & SU \\
45 & Jembatan Desa & B.KB.9c & 16,02 & JP \\
\hline & & & & \\
\hline
\end{tabular}

Nilai skor prioritas aset-aset jaringan irigasi pada Daerah Irigasi Kedung Bantal telah diurutkan berdasarkan urutan dari yang terkecil hingga yang terbesar dapat dilihat pada tabel 9 diatas, sehingga dapat diperoleh urutan penanganan yang harus dilakukan terlebih dahulu. 


\section{KESIMPULAN}

Daerah Irigasi Kedung Bantal dimana penelitian dalam studi ini dilakukan diperoleh kesimpulan sebagai berikut:

1. Penelusuran jaringan irigasi Kedung Bantal pada tahun 2019 menghasilkan kesimpulan bahwa kondisi aset irigasi pada Daerah Irigasi Kedung Bantal pada dasarnya masih baik.

2. Penilaian indeks kinerja sistem irigasi pada Daerah Irigasi Kedung Bantal Kecamatan Pagerwojo Kabupaten Tulungagung dengan menggunakan software PDSDA-PAI Versi 2.0 didapatkan $77,35 \%$, sedangkan menggunakan blangko didapatkan nilai indeks kinerja $74,13 \%$ sehingga diperoleh selisih $3,22 \%$. Selisih yang ada dikarenakan adanya beberapa perbedaan seperti parameter kondisi dan penilaian kondisi.

3. Berdasarkan analisa skala prioritas penanganan untuk prasarana fisik menggunakan software PDSDA-PAI Versi 2.0 diperoleh prioritas penanganan utama pada Daerah Irigasi Kedung Bantal yaitu Bangunan Ukur (B.KB.2b), berikutnya Talang (B.KB.2m) dan prioritas yang terakhir adalah Jembatan Desa (B.KB.9c).

\section{Daftar Pustaka}

[1] Kementerian Pekerjaan Umum, Peraturan Menteri Pekerjaan Umum dan Perumahan Rakyat Republik Indonesia Nomor 12/PRT/M/2015 tentang Eksploitasi dan Pemeliharaan Irigasi. Jakarta: Departemen Pekerjaan Umum dan Perumahan Rakyat, 2015

[2] Kementerian Pekerjaan Umum, Peraturan Menteri Pekerjaan Umum dan Perumahan Rakyat Republik Indonesia Nomor 23/PRT/M/2015 tentang Pengelolaan Aset Irigasi. Jakarta: Departemen Pekerjaan Umum dan Perumahan Rakyat, 2015

[3] Kementerian Pekerjaan Umum, Kriteria Perencanaan 01 Bagian Jaringan Irigasi. Jakarta: Direktorat Jendral Pengairan Departemen Pekerjaan Umum, 2010

[4] Kementerian Pekerjaan Umum, Undang-Undang Republik Indonesia Nomor 7 Tahun 2004 tentang Sumber Daya Air. Jakarta: Presiden Republik Indonesia, 2004

[5] Kementerian Pekerjaan Umum, Pedoman Penilaian Kondisi Fisik Jaringan Irigasi Tahun 2010. Jakarta: Departemen Pekerjaan Umum, 2010

[6] Soewarno, Hidrologi Untuk Teknik. Bandung: Penerbit Nova, 1995

[7] Bambang Triatmodjo, Hidrologi Terapan Cetakan Kedua. Yogyakarta: Beta Offset, 2010

[8] Kementerian Pekerjaan Umum, SNI 8284:2016 tentang Tata Cara Pemeliharaan Jaringan Irigasi Teknis. Jakarta: Badan Standardisasi Nasional, 2016

[9] Kementerian Pekerjaan Umum, Peraturan Menteri Pekerjaan Umum dan Perumahan Rakyat Nomor : 33/PRT/M/2016 tentang Petunjuk Teknis Penyelenggaraan Dana Alokasi Khusus Bidang Infrastruktur. Jakarta: Departemen Pekerjaan Umum dan Perumahan Rakyat, 2016

[10] Kementerian Pekerjaan Umum, Pedoman Teknis Rehabilitasi Jaringan Irigasi. Jakarta: Direktorat Jenderal Prasarana dan Sarana Pertanian, 2017 